\title{
Pedagogical Potential of the Folk Calendar in the Educational Process of Primary School
}

\author{
Irina E. Kashekova ${ }^{1^{*}}$ \\ ${ }^{I}$ Federal State Budget Scientific Institute of Art Education and Cultural Studies of the Russian Academy of Education, \\ Pogodinskaya St., 8/1, Moscow, 119121, Russia \\ *Corresponding author E-mail: ikashekova@bk.ru
}

\begin{abstract}
The article reveals the possibilities of improving the quality of education in the context of an interdisciplinary integrated approach to learning based on immersion in traditional culture and mastering a universal complex of folk calendar, which possesses a striking pedagogical potential in the formation of a holistic view of the world, the development of strategic and associative thinking, and instilling of environmental culture of the individual. The pedagogical potential of the folk calendar is an optimal complex that integrates into education various fields of knowledge, such as natural cycles and phenomena, geographical features of the area and the encompassing landscape, local historical collisions, customs and folklore, folk beliefs and fairy tales, and the specifics of folk ornaments decorating household items and tools of trade. The study of the folk calendar complex in primary or basic school makes it possible providing a holistic presentation of learning material scattered in different subjects. Integrating the content of subjects studying the world around us, such as mathematics, literary reading, the Russian language, visual arts, music, and technology will help the child to understand not only the diversity and richness of the world, but also the existing interconnections. At the same time, games, proverbs, sayings, bright and expressive folklore images, images of mythological characters will cause interest of the child, and thus help him to master new information on various subjects at the emotionally positive background.
\end{abstract}

Keywords: culture, cultural memory, art, traditional culture, folk calendar, educational process, integration, interdisciplinarity, emotional experience, world view, image.

\section{Introduction}

At the heart of the John Dewey's concept, well-known in pedagogy, which represents the trajectory from the child to the world, and from the world to the child, is the idea of the expediency of the involving of the child in the educational process, based on his individual experience. The scientist focused on the value interpretation of experience, since the attitude of a person to the world around is not just contemplative-theoretical and dispassionate [1]. Any practical attitude, as well as practical activity, are always emotionally colored, carry subjective preferences, and include personal evaluation. Dewey's concept is based on the same principle that underlies any traditional culture, with the only difference that the place of the child was occupied by an adult. The trajectory of a person's life path, all his experience from birth to death, is reflected in the age-old wisdom of the folk calendar, with strictly regulated cycles and rules. The complex of the folk calendar possesses a striking pedagogical potential in the formation of a holistic view of the world, the development of strategic and associative thinking, and instilling environmental culture of the individual. It is known that any experience, whether acquired in life or imagined, is referred to both culture and memory. Here, there is a mutual connection: the experience of life collisions and their emotional perception determine the human experience, while the accumulated available experience determines the future actions and fantasies that result in a new experience and enriches cultural memory.
With regard to the "cultural memory", in 1920-1930-s, outstanding Russian psychologists L.S. Vygotsky and A.R. Luria wrote in their "Etudes on the history of behavior": "We have deliberately stopped more in detail on the function of memory, because it gives us the opportunity to illustrate the relationship of natural, inherent in nature, and cultural, acquired in the course of social experience, forms of mental activity. It was here that we saw that the development turned out to be not just maturation, but cultural metamorphoses, cultural rearrangement. And if we now wanted to consider the memory of an adult cultural person, we should have taken it not so much as it was created by the nature, but as it was created by the culture" [2].

The interest in memory that has found support in the art culture, allows feeling the past in contemporary conditions and understand that the culture of the past centuries determines the development of the culture of the future. Experience gives the opportunity to interpret culture and memory [3].

Folk culture reflects the way of thinking, temper, value orientations and life attitudes peculiar to social or ethnic communities, nations, peoples, and ethnic groups. The consciousness of each person, as a member of collective, correlates with the collective consciousness reflected in art, symbols, rituals, language, and forms of life organization. Cultural memory creates a universal interaction space between the way of thinking and practice. In contrast to individual or collective memory, its specificity consists in the translation and actualization of cultural meanings. Cultural memory keeps the generalized "knowledge", it activates people's activity and communication, common experiences, which were 
repeated from generation to generation, and fixed in the memory of social groups and in society in general.

In the classification of all types of memory, cultural memory is defined as the transfer of meaning or messages important for society. Recently cultural memory received the name of "cultural texts" [4, 5]. Cultural texts include rites and rituals because their function is to preserve, transmit, and resurrect cultural meanings. Cultural memory, as it were, fixes certain circumstances that, going into the past, turns into images and is preserved in the form of symbolic codes. The cultural memory bearers are priests, shamans, bards, artists, writers, scientists, and teachers. Moreover, the cultural memory mechanisms have their own specifics in different "information and communication eras" [6]. The past is reconstructed in the cultural memory $[7,8]$.

The folk calendar is the universal cultural memory bearer. The memory stored by the folk calendar has been functional for many centuries, as it contributed to the development of culture. The folk calendar was a link between the past, present, and future, it kept and transferred the values establishing features of identification and norms of behavior.

Combination of individual data into the integral, broad world view, such that was perceived by our ancestors, can be constructed in the course of acquaintance with a complex of a folk calendar. Being a complicated cultural phenomenon, folk calendars of each ethnic group had been formed over a long period. Each of peoples were founding their own methods of time reckoning, corresponding to their mentality, which served the basis of a calendar with very large (century, era) and quite small (day, night) time units. The development of calendars was influenced by many reasons of both ideological and domestic nature, which determined their specificity and content. Being a system of time reckoning, the calendar "... of any peoples ... is full of a variety of diverse elements that have different origins, their rate of evolution, and a special functional purpose" [9].

In the research of scientists, it is noted that "the creative essence of folk traditions, rituals, and customs returns only when they are updated in connection with new conditions, attitudes, and views, that makes it possible to preserve them, but in a modern up-to-date version relevant for the given time" [8].

\section{Methods}

The well-formed structure of folk calendars surprisingly soaks up all the multidimensionality and diversity of peoples' life. Therefore, the familiarization of pupils with the calendar adopted in the cultural tradition of their country will be particularly effective if conducted on an interdisciplinary, integrated basis.

Invented in ancient times, the calendar fixes years, seasons, months, dates, and days. It reflects the periods of natural phenomena based on the constant celestial motion of the Moon, Sun, and the stars. The ordered time reckoning resulted from a long development of human consciousness, his observations of the nature and long-term experience of existence, but, at the same time, the calendar became also a necessary condition of development of a civilization.

People's judgment endowed the calendar with consecrated-secular entirety. "Any religious world view is based on the opposition between the sacred and the secular. These two areas, in which the life of a religious person takes place, mutually exclude and mutually assume each other" [10].

Calendars, formed in the folk environment, carried in their ideological basis an amazing synthesis of mythological ideas and real practical experience. This is especially close to primary school pupils, who are at the beginning of the path of mastering the cultural experience of mankind, and their thinking has not yet lost its mythological nature [4].

The pedagogical potential of the folk calendar represents an optimal complex that integrates various fields of knowledge in education. This knowledge includes natural cycles and phenomena, geographical features of the area and the encompassing landscape, local historical collisions, customs and folklore, folk beliefs and fairy tales, and the specifics of folk ornaments decorating household items and tools of trade.

In the system of primary general and additional education, the reference to the folk calendar can become the optimal form of integrated education. Familiarization with the complex of the folk calendar is important in both the junior and the teenage years. Though, different tasks are solved in these two cases. Studying the complex of the folk calendar in primary or basic school, we get the opportunity for a holistic presentation of learning material distributed in different subjects. Integrating the content of subjects describing the world around us, such as mathematics, literary reading, the Russian language, visual arts, music, and technology will help the child to understand not only the diversity and richness of the world, but also the existing interconnections. At the same time, games, proverbs, sayings, bright and expressive folklore images, and mythological characters will cause interest of the child, and thus will help him to master new information on various subjects on an emotionally positive background.

When studying human consciousness at the early stages of culture, as well as religious consciousness, P. Florensky developed the concept of "night" consciousness, which, as he believed, was peculiar to all the archaic cultures, and which is peculiar to folk cultures [11]. In a certain sense, "night" consciousness can be attributed to the early thinking development stages of the today's child. It is the level of children's preparedness, the abilities of educational institutions and professional competences of teachers that determine the forms and build the learning trajectory in a particular educational and upbringing process.

The relevance of the integration of different areas of knowledge based on the content of the folk calendar in the modern teaching and educational process is necessitated by the following: 1) searching for optimal pedagogical conditions of a holistic approach to the knowledge and understanding the world around; 2) forming personal life stance based on the values of the traditional culture of their peoples; 3 ) developing emotional-figurative perception, associative thinking, and intuition, necessary for successful implementation in the modern socio-cultural space.

This requires solving the following tasks:

- identifying pedagogical and educational potential of traditional cultures;

- developing folk traditions in the arts and crafts classes in the system of general, additional, and vocational education;

- conducting education on the basis of the study of traditional culture heritage of the world, adapting it to contemporary social and cultural needs of society;

- defining pedagogical conditions of spiritual and moral development of children of different age groups.

The development of the folk calendar involves integrated forms of immersion of the pupil in the cultural traditions of the region. The construction of the teaching and educational process at the school on the cultural and activity-based approaches using the principles of complementarity and interchange of knowledge from different educational areas, their correlation with the folk tradition of knowledge of the world around involves interdisciplinary crosscultural links of learning and art content, and the reliance on the concept of "image" [12]. Exploratory heuristic forms of school classes go beyond the lesson into a broad general cultural space. All this has a significant impact on the child's development and contributes to the quality of education.

The pedagogical potential of the folk culture in the development of the contemporary child, and the expansion of his horizons, is extremely large, provided its proper use. Therefore, we offer to include topics related to the folk calendar simultaneously in different school subjects. In this case, the teaching and educational process is based on the cultural approach, which is focused on the application of the cultural traditions that have formed the social ideals, tastes, and values, which correspond to the peculiarities and mentality of the nation. The mastering of cultural traditions en- 
sures the child's conscious penetration into culture, understanding the need to preserve and develop it.

Given that the purpose of the educational process is learning, while the ranking of priority activities for primary school pupils is based on a game - work - communication - knowledge succession [13], it is important to build the learning process in such a way as to provide pupils easy and direct knowledge absorption proper for their age through play, work, and communication. This can be fully achieved through mastering of the folk calendar. The integrating mechanism and material resulted from this activity will be the collective work of schoolchildren towards creating the folk calendar image at art lessons or in additional study sessions.

Today such form of collective work as a "team building" is used worldwide. Team building is usually used as a business game, which aims at creating the matched team. The game includes a range of active actions towards developing the skills of solving jointly the common problems through the team efforts. Such training is currently conducted for employees of large and quite successful companies. This performs the functions of getting in tune with team members in the course of problem solving, the ability to subordinate their interests to a common goal, acquiring skills for mutual assistance, support, and devotion to their team. It is extremely important in the context of children's group. Thus, in the course of solving the task, we not only expand the pupils' horizons, acquaint them with native culture traditions, but also prepare children for future professional activities in the team.

Artistic and creative result of such school classes consists in creating a collective panel of the "Image of the folk calendar". Children can approach towards this goal in different ways. The path is chosen by the teacher (or educator in the additional education system) depending on the specific conditions, i.e. the time allotted for work, available materials, teaching and educational tasks, as well as children preparedness and motivation.

Path 1. It seems to us that the ideal result can be achieved by combining the efforts of teachers in different educational areas and familiarity with the specifics of the folk calendar from different perspectives in the framework of different subjects. In primary school it can be literary reading, The Russian language, the world around, art, music, technology, and physical culture. In this case, the educational process (at least for some time) will acquire integrity, and provide connection, necessary in the contemporary world, between disparate knowledge obtained in the framework of different subjects.

This path will allow children to:

- reveal the features of traditional worldview and world perception based on deep respect for nature and its phenomena;

- touch the specifics of the language, as well as to comprehend the expressiveness and depth of folk proverbs, sayings, and riddles;

- participate in the reconstruction of the most popular folk fests with their ritual basis (meaning, attributes, songs, dances, and outdoor games);

- comprehend the celestial motion principles of the Sun, Earth, and Moon, as well as get acquainted with different types of their interaction models;

- conduct mathematical calculations related to the celestial motion of the Sun, Moon, and Earth, as well as the change of seasons, weeks, and days, which allow evaluating the observation and wisdom of the folk;

- understand the specifics of the symbolic image and picture writing;

- learn how and what the household items, tools, dwelling, and clothing were made from, what is the meaning of the ornaments used to decorate the dwelling and clothing.

In the case of the implementation of an integrated approach to the study of the folk calendar, teachers work together to develop an action plan so that the information received by children during different lessons would be consistent and complementary [12] Knowledge of pupils is visualized at the fine art lessons, where they find an artistic form and are embodied in a collective panel "Image of the folk calendar".
Path 2. The teacher of fine arts includes the topic of the "Image of the folk calendar" into his work program. At least two lessons should be selected to this work. Part of the first lesson is used to acquaint children with the folk calendar as a significant cultural phenomenon. Teacher discusses the specificity of the images of various folk calendars. Then the team work is carried out on creating the panel.

Path 3. The third path is the continuation of the path 2 during pupils' free time (on the mug, creative workshop, or during the extra activity) with a more detailed insight into the contents of the folk calendar, and meticulous attention to the details.

Path 4. In the frameworks of additional education system, several weeks to several months can be devoted to the study of the folk calendar to create joint calendar panel through the team work. In case of long-term work, one can include preliminary prepared drawings and sketches, work with illustrated books, and visit the Museum of Folk Life and Decorative and Applied Arts. Children can draw up ornaments and images of peasant labor and life, make sketches of landscapes at different times of the year, create works of art reflecting peasant labor, etc. From all the accumulated material, children can create a collective panel, using different artistic materials, including ceramics, tapestry, embroidery, batik, etc.

\section{Results}

The folk calendar is one of the most perfect cultural heritages. It includes a variety of interrelated views, opinions, and recommendations to various activities that in their totality determined human's course of life. According to Russian psychologists, activity still is the basis for the world cognition by a growing up person [2] The integrative nature of the folk calendar allows including it in a variety of educational areas and thus revealing to the child a holistic image of the world - the image, which people had perceived before. This will become the basis for the formation of a modern worldview, which will include both scientific and mythological components, as well as artistic, folk, emotional and value elements, traditional for a particular culture.

The scientific component reveals the laws of natural phenomena, such as the change of seasons, months, and days; alternation of day and night; mathematical time reckoning; geographical features of the natural landscape and associated seasonal works and holidays in the particular region. It plunges deep into the centuries, helps to present in historical retrospect, as people lived before.

The mythological component introduces the traditional ideas, beliefs, images of ancient deities and contemporary religious beliefs, amulets and associated superstitions, ancient semantics and its transformation in the images of folk and professional art.

The traditional component helps understanding the spiritual and moral criteria and values of traditional art, comprehending the meaning of some words that came to us from the old days, purpose of household items, tools of labor, and ornament elements; as well as learning the meaning of names.

The artistic component teaches perceiving and evaluating the surrounding world and the art from the aesthetic standpoint and reveals the meaning of the images on traditional dishes, tools of labor, decoration items, clothes, and dwellings; it teaches distinguishing solar symbols, reading and making symbolic writing, which served the prototype of the modern pictograms.

The folklore component gives an idea about folk festivals and everyday life, as well as how the worldview of man was expressed in proverbs, sayings, tales, rites and rituals based on songs, dances, and games; it reveals the traditional roots of some modern children games and toys.

The emotional and value component reveals the normative essence of people's life, namely the rules of coexistence, the values of nature, country, home, family, harvest, bread, villagers, townsfolk, etc.

The complexity and diversity of the folk calendar, comprehensively learned in the framework of different subjects, allows achieving 
the holistic development of personality in multicultural and multiart environment, getting into the culture by mastering its most important spatial and temporal structures, rather than achieving just individual educational effects.

\section{Discussion}

An important problem of contemporary education is improving its quality. Therefore, new approaches and forms of modernization of the educational process content and methods are being developed everywhere. Many factors of the today's world require revising the traditions that have developed in education. The mosaic thinking typical of contemporary children can be adjusted only at a holistic, panoramic presentation of information, involving personal experience and associative memory, spontaneously providing images formed in the emotional experience of pupils, as well as referring to the cultural memory of mankind. The principles of mutual exchange and complementarity between science and art, tradition and modernity, word and image, linguistic diversity including using additional languages $[4,12,14,15]$ of different educational areas, and reliance on the personal emotional experience will help child to increase the interest in learning, motivate self-learning, and stimulate creativity.

In this regard, a special role is played by various art terms, because art is the guarantor of "the world perception in its integrity, rather than in its individual aspects", as well as the guardian of "the integrity of the individual, the integrity of culture, and the integrity of the life experience of mankind" [16].

\section{Conclusion}

The information, laid down in the folk calendar, integrates knowledge from many areas of both primary and basic school, such as literary, historical, mathematical, geographical, biological, astronomical, artistic, musical, technological and practical disciplines. In this context, the spatial and temporal structure of the folk calendar is of particular importance. Taking into account that the space and time categories are presented in different angles by physics, biology, mathematics, and psychology, while their reflection is discussed in literature, music, visual and spatiotemporal arts, the use of the complex of the folk calendar in the contemporary teaching and educational process looks quite attractive and promising. The interrelated abstractions of space and time, which can be partially experienced by observing their changes in the natural environment, and partially - by tracing the digital measurements of these categories [17], are also perceived in artistic images. The importance of this factor is determined by the statement of contemporary psychologists that "a person perceives the world around him by images, rather than by the body of knowledge. Knowledge is ordered and embody the images into a system" [18].

The objectivity of the time and space categories in the exact sciences, and their symbolism in the works of art is fully revealed in the content of the folk calendar, combining amazingly real and fantastic, objective and subjective, abstract and concrete, conditional and unconditional.

\section{Acknowledgement}

We would like to express our gratitude to the administration and teachers of the "Hellas" gymnasium (Moscow), who took part in conducting the experiment. Due to selfless creative work of V.A. Sidorov, A.A. Podchernyaev, T.Yu. Golitsina, I.A. Savchenko, A.G. Petrova, O.A. Mikhaleva, and S.V. Tikhonov, children have mastered the world in its totality, gaining knowledge on a positive emotional background and building their educational trajectory.

\section{References}

[1] Dewey J (2009), Ot rebenka $-k$ miru, ot mira $-k$ rebenku [From child - to world, from world - to child]. Moscow, Karapuz, 352 p.

[2] Vygotsky LS, Luria AR (1993), Etyudy po istorii povedeniya: Obez'yana. Primitiv. Rebenok [Etudes on the history of behavior: Primate. Primitive. Child]. Moscow, Pedagogic-Press, 224 p.

[3] Vasilyev AG (2012), Kul'turnaya pamyat'/zabvenie i nacional'naya identichnost': teoreticheskie osnovaniya analiza [Cultural memory/oblivion and national identity: Theoretical basis of analysis]. Cultural memory in the context of the national identity formation of Russia in the XXI century: Collective monograph. Russian Institute of Cultural Studies. Moscow, Coincidence, pp: 3-29.

[4] Lotman YuM (1998), Ob iskusstve [About the art]. St.Petersburg, Art, $704 \mathrm{p}$.

[5] Lotman YuM (2001), Semiosfera [The semiosphere]. St.Petersburg, Art, $704 \mathrm{p}$.

[6] Khristoforova OB, Antonov DI, Akhmetov MV, Petrov NV (2014), Mekhanizmy kul'turnoj pamyati: ot fol'klora do media [Mechanisms of cultural memory: From folklore to media]. Abstracts of the International scientific conference. Moscow, Russian Academy of National Economy and Public Service.

[7] Arnautova YuA (2006), Kul'tura vospominaniya i istoriya pamyati. [Culture of recollections and history of memory]. History and memory: The historical culture of Europe until the early modern period. Moscow, Krug, pp: 47-55.

[8] Assman Ya (2004), Kul'turnaya pamyat': Pis'mo, pamyat' o proshlom i politicheskaya identichnost' v vysokih kul'turah drevnos$t i$ [Cultural memory: Writing, memory of the past and political identity in the high cultures of antiquity]. Moscow, Slavic culture languages, $368 \mathrm{p}$

[9] Nekrylova AF (1991), Kruglyj god. Russkij zemledel'cheskij kalen$d a r^{\prime}$ [The year round. Russian agricultural calendar]. Moscow, Pravda, $496 \mathrm{p}$.

[10] Garadzha VI (2005), Sociologiya religii [Sociology of religion]. Moscow, $348 \mathrm{p}$.

[11] Florensky PA (1977), Iz bogoslovskogo naslediya [From the theological heritage]. Theological Works, 17.

[12] Kashekova I (2016), Interdisciplinary concept of "image" in the cross-cultural pedagogical technology of "ART+". The European Proceedings of Social and Behavioral Sciences, pp: 300-306.

[13] Tretyakov PI, Sennovsky IB (2001), Tekhnologiya modul'nogo obucheniya $v$ shkole [Technology of modular education at school]. Moscow, New school, $352 \mathrm{p}$.

[14] Ageev VN (2002), Semiotika [Semiotics]. Moscow, Entire World, $256 \mathrm{p}$.

[15] Bohr N (1961), Atomic physics and human knowledge. New York, Publishing House of Foreign Literature, $112 \mathrm{p}$.

[16] Borev YuB (1975), Estetika [Aesthetics]. Moscow, Publishing House of Political Literature, $400 \mathrm{p}$.

[17] Efremova EN (2003), Hronotop v zhanre romana literatur narodov Severnogo Kavkaza [Chronotope in the genre of novel of the North Caucasus peoples' literature. Experience of comparative study]: dissertation of Ph.D. (Philological sciences). Nalchik, $165 \mathrm{p}$.

[18] Zinchenko VP, Nazarov AI (1991), Razmyshleniya ob iskusstvennom intellekte [Reflections on artificial intelligence]. O chelovecheskom $v$ cheloveke [About humanities in human]: monograph edited by Frolov TI. Moscow, Politizdat, pp: 121-138. 